\title{
The experience of adolescence in rural Amhara Region, Ethiopia
}

\author{
Annabel Erulkar \\ Population Council \\ Tekle-Ab Mekbib \\ Population Council
}

Negussie Simie

Tsehai Gulema

Follow this and additional works at: https://knowledgecommons.popcouncil.org/departments_sbsr-pgy

Part of the Demography, Population, and Ecology Commons, Family, Life Course, and Society Commons, Gender Equity in Education Commons, and the International Public Health Commons How does access to this work benefit you? Let us know!

\section{Recommended Citation}

Erulkar, Annabel, Tekle-Ab Mekbib, Negussie Simie, and Tsehai Gulema. 2004. "The experience of adolescence in rural Amhara Region, Ethiopia." Accra: Population Council. 


\section{The Experience of Adolescence in}

Rural amhara Region Ethiopia 


\section{The Experience of Adolescence in Rural Amhara Region Ethiopia}

Annabel S. Erulkar

Tekle Ab Mekbib

Negussie Simie

Tsehai Gulema 


\section{(2) Population Council}

The Population Council is an international, nonprofit, nongovernmental organization that seeks to improve the wellbeing and reproductive health of current and future generations around the world and to help achieve a humane, equitable, and sustainable balance between people and resources. The Council conducts biomedical, social science, and public health research and helps build research capacities in developing countries. Established in 1952, the Council is governed by an international board of trustees. Its New York headquarters supports a global network of regional and country offices.

(c) 2004 by The Population Council

Population Council

P.O. BOX CT 4906

Accra, GHANA

Tel: (233) $21-780712 / 2$

Fax: (233) $21-780713$

\author{
Population Council \\ One Dag Hammarskjold Plaza \\ New York, NY 10017 USA \\ Tel: 212-339-0500 \\ Fax: 212-755-6052 \\ http://www.popcouncil.org
}

Annabel S. Erulkar, MSc, PhD is Program Associate at the Population Council's Regional Office for sub-Saharan Africa in Accra, Ghana.

Tekle-Ab Mekbib, MD, PhD, is Medical Consultant for the Population Council in Addis Ababa, Ethiopia.

Negussie Simie, MA, is Head of the Planning, Programming and Training Department, Ministry of Youth Sports and Culture, Ethiopia

Tsehai Gulema, MA is Head of the Youth Policy, Research and Implementation Department, Ministry of Youth Sports and Culture, Ethiopia

Photo credits: UNICEF Ethiopia 


\section{FORWARD}

The rights and well-being of the children and youth are firmly held values of the Federal Democratic Republic of Ethiopia (FDRE). The recently proclaimed Youth Policy by the Government of the FDRE is a manifestation of this commitment, and is indeed a historical milestone in the effort to improve the lives of adolescents and young people in the country. Ethiopia is a signatory to the Convention on the Rights of the Child and fully supports the International Conference on Population and Development (ICPD) recommendations making adolescent reproductive health an area of special attention.

As such, the Ministry of Youth, Sports and Culture has long considered attention to the lives of Ethiopian adolescents as a priority intervention area for research and programs in the country. This study gives critical insight into the lives of adolescent girls and boys in Ethiopia. Whereas youth programs tend to treat all adolescents as similar, or indeed homogeneous, the findings of this study highlight the remarkable diversity of young people in Ethiopia. The study highlights that many young people live without parents; that many are out of school while they value education; that many adolescents are survival workers who are at risk of exploitation and abuse; and that marriage can be an unwanted event in the lives of adolescent girls. The study teaches us to recognize that not all adolescents are the same and that some adolescents are in highly vulnerable situations, such as domestic workers and victims of forced early marriage. Likewise, the study teaches us that programming for young people needs to recognize this diversity, and move toward finetuning models to reach the most vulnerable, at-risk youth.

It is the hope of the Ministry of Youth, Sports and Culture that the findings from this study can be fully integrated into appropriate programs for Ethiopian girls and boys in all areas of the country. On behalf of the Ethiopian Government, I would like to express my deep appreciation to the partners accompanying us in the struggle to improve the lives of girls and boys in Ethiopia, in paving the way for a healthy and prosperous Ethiopia in the future.

\section{Ambassador Teshome Toga} Minister, Youth, Sports and Culture 


\section{TABle of Contents}

Executive Summary ....................................................................... vii

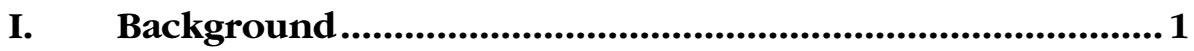

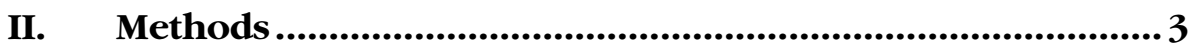

$2.1 \quad$ Formative research ........................................................ 3

2.2 Quantitative research ..................................................... 3

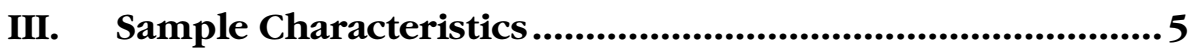

IV. Parental Survivorship \& Presence ..................................6

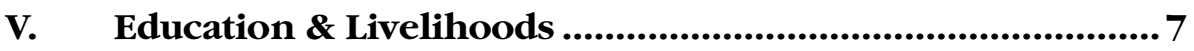

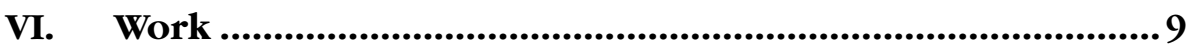

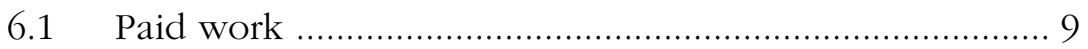

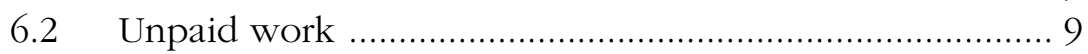

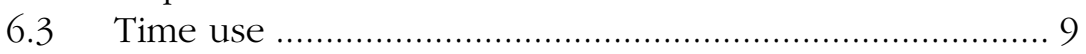

VII. Social Networks, Support, \& Mobility ................................ 10

VIII. Reproductive Health \& Experience with HIV/AIDS ........... 12

IX. Exposure to HIV/AIDS Messages ....................................... 14

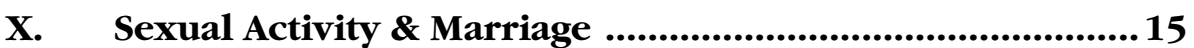

10.1 Marriage and education ................................................. 16

10.2 Decision-making and consent to marry ........................ 17

10.3 Post marital living arrangements .................................... 18

10.4 Spouses and partnerships ............................................. 18

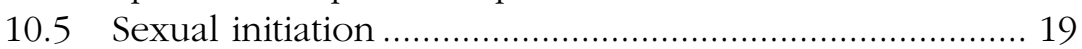

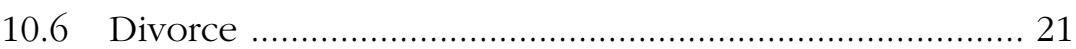

XI. Pregnancy \& Births .......................................................... 21

11.1 Prenatal care and childbirth ........................................... 21

XII. Implications for Programs .................................................. 22

12.1 Recognize the diversity of young people ...................... 22

12.2 Design programs that are appropriate to the context of young lives ................................................ 22

12.3 Programs to reduce social isolation ……........................ 22

12.4 Programs to delay marriage and support married adolescent girls ............................................................. 23

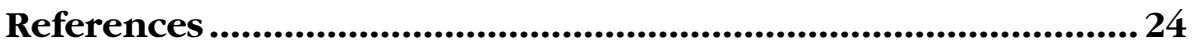




\section{Tables \& Figures}

Table 1 Median age at marriage and percentage of girls married by age 15 and 18 , by region

Table 2 Sample characteristics, by sex of the respondent 5

Table 3 Parental survivorship, parental residence, and fostering experiences, by sex.....

Table 4 Education, vocational training and literacy, by sex 7

Table 5 Community support, perceptions of safety and experience of crime, by sex

Table 6 Participation in social events and media exposure, by sex.

Table 7 Reproductive health knowledge, by sex

Table 8 Exposure to HIV/AIDS information in the last year, by sex and marital status

Table 9 Girls' knowledge and consent to marriage, by age at marriage

Table 10 Girls' living arrangements following marriage, by age at marriage

Table 11 Context of sexual initiation, by age at marriage 20

Figure 1 Time use of adolescents, by sex and school status 9

Figure 2 Cumulative proportion of boys and girls who are married, by age 


\section{ACKNOWLedgements}

This study would not have been possible without the support and guidance of a great many institutions and individuals. We appreciate the support and assistance of the Ministry of Youth Sports and Culture, the Regional Youth Bureaus, and Kebele officials in facilitating our work. We gratefully acknowledge the support of UNICEF, UNFPA, United Nations Foundation, Turner Foundation, and DfID in making this study possible. Thanks go to Judith Bruce and Lisa Bohmer for guidance during conceptualization of the study, to Assefa Hailemariam for assistance with training and data collection and to Lucy Ng'ang'a for data management. We wish to thank Judith Bruce, Nicole Haberland, and Mirgissa Kaba for their thoughtful comments on earlier drafts of this report. Finally, we thank the young people themselves who were so giving of their time, ideas and experiences and from whom we have learned a great deal about what it is to be an adolescent in rural Ethiopia. 


\section{EXecutive Summary}

This study aims to broaden the understanding of young lives in rural Ethiopia, specifically, Amhara Region. The study included initial in-depth interviews among selected adolescents, followed by a large-scale survey of over 1,800 young people aged 10 to 19 in rural Amhara Region, Ethiopia. Just over half of the adolescents in the sample had never been to school. The most common reason for boys and girls not attending school was poverty, followed by early marriage for girls, and too many work responsibilities for boys. Even among those who had been to school, entry was quite late and educational attainment was low. Nearly one third of students first started school after age 10 and school-going adolescents only attended for an average of 3 years. As a result over half of the adolescents interviewed were illiterate.

Few rural young people had ever worked for pay. Rather, the majority were involved in unpaid work for their families, most on the family farm. The time devoted to unpaid work was considerable, especially for out of school adolescents. Both boys and girls devoted an average of over 30 hours per week to unpaid work, most of which was agricultural work.

Boys appeared to have more friends and better social support than girls. Not only did boys report more friends, but more boys than girls said that they have a place to meet their same sex friends, have a place to stay if they needed it, and have someone from whom they could borrow money. Boys' social connections and mobility are evident in their greater exposure to social events and to media, as well as their greater exposure to HIV messages through various means. Conversely, those who have the fewest friends, who have the most limited exposure to media, and who are the least likely to be reached with HIV information are married adolescent girls.

The reproductive health knowledge of rural adolescents was quite low. Young people had high awareness of family planning methods such as pills and injectables. They were also knowledgeable about basic information on HIV, including that there is no cure for AIDS and that a healthy looking person can be infected with HIV. Only 44 percent of boys and 27 percent of girls were aware of condoms, which is alarming given the rates of HIV infection among young people, especially girls, and the high rates of infection in Amhara region. Further, many young people perceived of HIV as a disease transmitted in towns, not in rural areas, which may give young people a false sense of protection against the disease.

Rates of marriage are much higher for girls than for boys. Fourteen percent of girls were married by age 10, and 39 percent were married by age 15 , while 4 percent of boys are married by age 15 . Only five percent of girls knew their husband beforehand; 15 percent of girls knew about the marriage before it happened; and only 20 percent of girls consented to be married. The younger the age at marriage, the less likely she was to have prior knowledge about the marriage or to give her consent. Sexual 
initiation was often early, unwanted, and forced. Among ever married girls, eighty-two percent did not want to have sex when they did and 81 percent reported that they were forced against their will to have sex. Sixty-nine percent of girls had first sex before they started menstruated. A surprising proportion of girls in the sample (12 percent) were already divorced or separated before their 20th birthday.

For 99 percent of girls and 86 percent of boys, first sex occurred within the context of marriage. This suggests that the timing of marriage drives the timing of sexual initiation and, indeed, the beginning of exposure to HIV and other types of reproductive risk. The study examined the context and experience of marriage among girls, with boys not included as there were too few married boys in the sample.

Just as the timing of marriage drove sexual initiation, so did it drive the timing of first birth. Thirty-seven percent of married adolescents had given birth, with some having as many as three children before their 20th birthday. Two-thirds of girls did not want the pregnancy at that time, feeling that they were too young to have a baby. Ninety-five percent of births took place in the home.

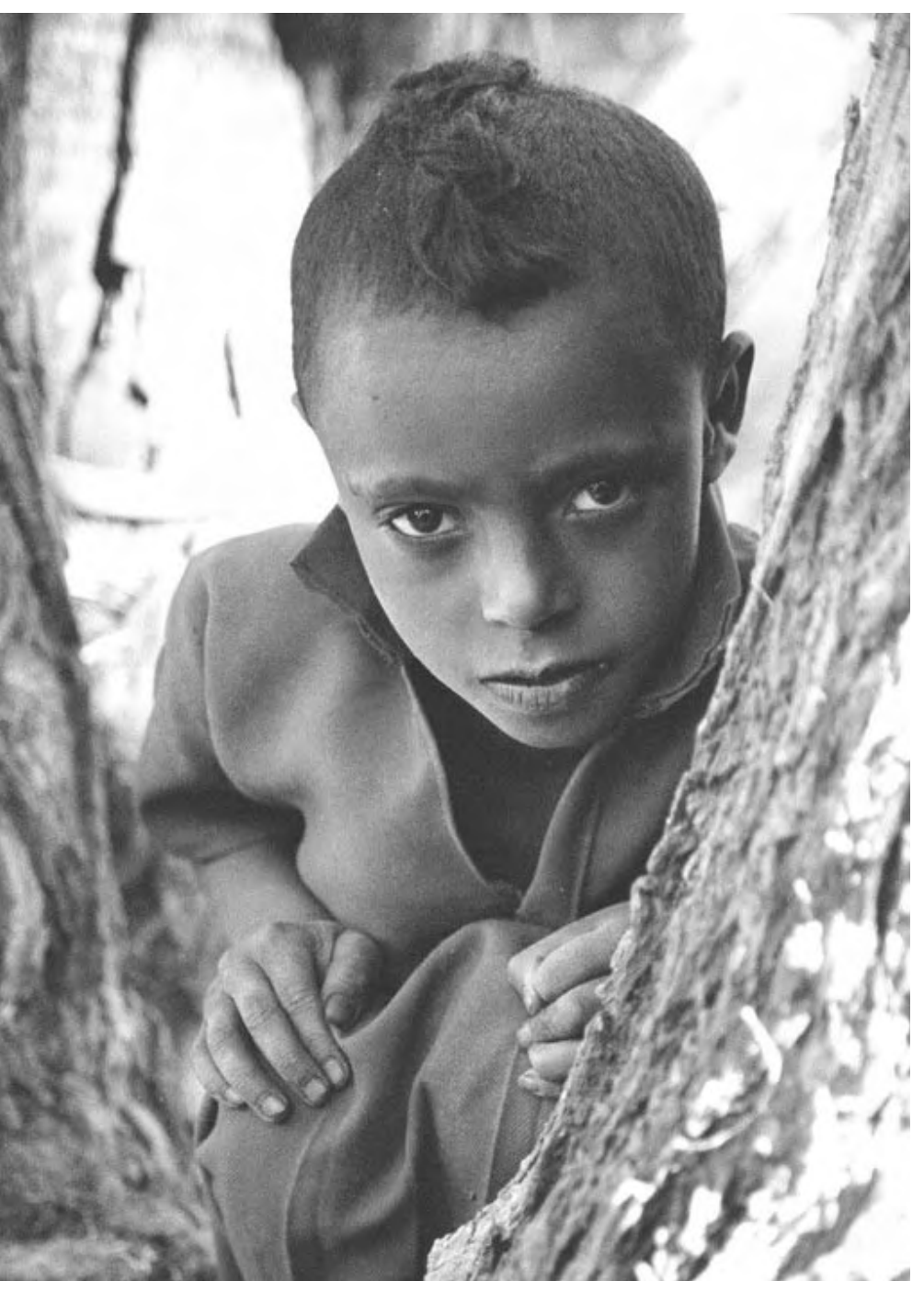

The study findings highlight programmatic needs of rural youth as well as neglected subgroups of adolescents. Educational participation rates are extremely low, suggesting that increased attention needs to be paid to expanding educational opportunities to adolescents in these areas. Adolescents are relatively isolated, have few friends, and have limited exposure to the outside world. This is especially true for girls and, especially, married adolescent girls. Programs should be designed that reduce social isolation and increase social support networks, especially for girls. Finally, married adolescents had the lowest exposure to HIV messages, yet may be at the highest risk. They also gave birth at extremely early ages, most without the support of medical care or personnel. Programs are needed to support married adolescent girls, increasing their social networks, giving them access to education and livelihoods opportunities, and providing them with support to manage reproductive risks they face.

As a result of this research, the Ministry of Youth Sports and Culture initiated a program for young people in rural Amhara region. The program is designed to delay marriage, support newly married girls, and provide safe spaces for the most vulnerable rural girls. 


\section{BACKGROUND}

There is increasing attention to adolescent ${ }^{1}$ reproductive health (ARH) in Ethiopia, especially because of high rates of HIV infection among this group as well as other reproductive morbidities and mortality. Studies have highlighted that sexual initiation and childbearing begins early in Ethiopia, with young people often having little knowledge and limited access to reproductive health (RH) services (Govindasamy et al, 2002). Many of the small-scale studies of Ethiopian adolescents have focused on selective groups of adolescents such as school-going adolescents or street children (Fekadu 2001, Versnel et al 2002, Adamu et al 2003). These studies contribute to our understanding of sexual initiation, family planning use, and risk behavior, especially among urban school-going youth. At the same time, 85 percent of Ethiopian adolescents reside in rural areas and the majority of adolescents are out-of-school (Population Council 2002). Few studies have focused on rural adolescents and few studies have had representative samples, covering in-school, out-of-school, and married adolescents. Moreover, only limited attention has been paid to the broad context of adolescent lives, above and beyond reproductive health issues.

While few studies have focused on the experience of child and adolescent marriage, Ethiopia is a country of extremely high rates of early marriage, especially in rural areas. Among urban girls aged 20 to 24, the median age of first marriage is high - over 24. However, for rural Ethiopian girls, median age at marriage is 17.6. In Amhara Region, specifically, median age at marriage for girls is 15 years, making marriage a common feature of girls' adolescence in the region (Table 1).

Table 1: Median age at marriage and percent of girls married by age 15 and 18 , by region $(n=2844)^{2}$

\begin{tabular}{lccc}
\hline & Married by age 15 & Married by age 18 & Median age at marriage \\
\hline Rural & 33.9 & 62.6 & 17.6 \\
Urban & 15.8 & 29.8 & Over age 24 \\
\hline Region & & & \\
\hline Addis Ababa & 6.6 & 16.9 & Over age 24 \\
Affar & 20.0 & 70.0 & 16.2 \\
Amhara & 50.2 & 79.9 & 15.0 \\
Ben Gumz & 31.3 & 63.2 & 16.8 \\
Oromiya & 10.3 & 42.6 & 18.7 \\
SNNP & 5.0 & 31.2 & 19.9 \\
Somali & 8.0 & 37.2 & 18.7 \\
Tigray & 26.1 & 68.8 & 16.4 \\
\hline
\end{tabular}

Source: Population Council Tabulations of Ethiopia DHS, 2000

${ }^{1}$ The target age group for this study was those aged 10 to 19 , the age group commonly c onsidered "adolescents." While we recognize that the terms "adolescents," "youth," and "young people," refer to slightly different age groups, we use the terms interchangeably in this report. ${ }^{2}$ Among girls aged 20 to 24 . 
Just as marriage is a feature of the adolescence for many Ethiopian girls, HIV/AIDS is increasingly touching the lives of young people in subSaharan Africa. A recent report from UNAIDS/WHO highlights that women, especially young women, are increasingly victims of HIV infection, with three quarters of HIV positive young people aged 15 to 24 being female (UNAIDS 2004). National estimates of adult ${ }^{3}$ HIV infection in Ethiopia range from 4.4 to 6.6 percent (UNAIDS/WHO 2004, MOH, 2002). Data from 34 sentinel sites in Ethiopia revealed the highest rates of HIV infection in two sites in Bahir Dar, in Amhara Region. Among pregnant women in Ethiopia, those with the highest HIV prevalence were young women in the age group 15 to 24 , with an estimated prevalence of 12.1 percent (MOH, 2002).

There is emerging evidence that marriage may pose a risk for HIV infection. A study that included biological markers in neighboring Kenya revealed that married adolescent girls had 50 percent higher rates of HIV infection compared to their unmarried, sexually active counterparts (Glynn et al 2001, Clark 2004). Once married, intercourse is much more frequent and condom use, virtually non-existent. Further analysis revealed that the husbands of married adolescents in Kisumu, Kenya are considerably older and much more likely to be HIV-infected compared to the boyfriends of unmarried girls (Clark, 2004). Notably, there are high rates of both early marriage and HIV infection in Amhara region, however data to explore the relationship between the two are lacking.

This study aims to broaden what we know about adolescence in rural Amhara Region, Ethiopia as well as to identify conditions that may exacerbate risk. It is drawn from a representative sample of adolescents and includes the range of adolescent experience, including in-school adolescents, out-of-school adolescents, and married adolescents. The study covers an array of issues to provide a broad and nuanced picture of young people's lives. The information is intended to provide programmers with greater understanding of young people and directions in designing appropriate programs for rural adolescents in Ethiopia.

${ }^{3}$ Adult prevalence refers to those aged 15 to 49 . 


\section{Methods}

The study was undertaken in Amhara Region and included two principle components. Qualitative, formative research was initially conducted in order to identify possible themes to be explored in the subsequent largescale quantitative survey.

\subsection{Formative research}

Qualitative, in-depth interviews were undertaken in Amhara Region among girls aged 10 to 19. In order to reflect the adolescent experience, girls from a range of experiences were selected including those who are married, unmarried, in school, and out of school. Respondents were identified by local leaders and requested to take part in the research. Previous research has revealed that young people may misreport or misrepresent information in the context of research, especially information of the most sensitive nature (Helitzer-Allen et al. 1994, Mensch et al. 2003). The study team surmised that young people may become more comfortable with the interviewer over time and therefore, more truthful. As a result, rather than interviewing each respondent only once, all selected respondents were interviewed three times by the same interviewer. The three sessions were used to cover a broad range of topic as well as to clarify issues that may not have been fully explored in previous sessions. Interviewers did observe that girls became more relaxed and perhaps more candid with each successive interview. As one interviewer noted:

Today the respondent was more relaxed than previous days. I raised some sensitive questions and she was happy to answer them. This shows the importance of visiting the respondent during several days. (Interviewer notes for session \#3 with married girl age 12, Ambara Region)

In all, twelve girls participated in the initial study, with each being interviewed three times over successive days, resulting in 36 interviews. An in-depth interview guide was developed for the study. The study sought to understand the broad context of girls' lives and, therefore, covered a range of issues. The topics included in the discussion guide were: living arrangements, time use and mobility, schooling, social networks and support, work, financial management, marriage, HIV/AIDS and reproductive health, and sexual behavior. The results of the study informed the design of the large-scale survey.

\subsection{Quantitative survey}

Following the formative research, a population-based survey of adolescents aged 10 to 19 was conducted in Amhara Region in early 2004. The survey took place in two Peasants' Associations, Mosebo Peasants' Association in Yilimana Densa Woreda and Enarmirt Peasants' Association in Mecha Woreda. The estimated population of these areas was 30,000 in Mosebo Peasants' Association and 16,000 in Enarmirt Peasants' Association, with households having an average of 5.2 members. In the initial stages of the study, all households in the study area were listed, collecting basic demographic information on all members of the household, regardless 
of age. A household was considered eligible for survey if it had an adolescent member aged 10 to 19, regardless of marital status. Eligible households were entered into the computer and 2,000 households were selected at random. The number of adolescents selected from each Woreda was proportion to the size of the population, with 600 selected from Mecha Woreda and 1,200 from Yilimana Densa. Where a household had more than one adolescent aged 10 to 19, a Kish grid ${ }^{4}$ (Kish 1965) was used to select just one adolescent.

The questionnaire used in the survey was a largely close-ended, structured instrument. Topic areas covered in the questionnaire were wide ranging, including household composition and assets, education, time use, migration, attitudes and expectations, reproductive health knowledge and practice, marriage, pregnancy and childbirth, and sexual activity. In addition, specific questions, especially those for which prior research was limited, were asked in an open-ended format. The questionnaire was translated into Amharic and back-translated to ensure accuracy.

Survey interviewers were recruited from the study areas and had a minimum of secondary education. Most had prior interviewing experience, especially with the census and other activities of the Central Statistical Authority, and were also recruited to be young enough so as to make respondents comfortable. Interviewers were trained for one day prior to the initial household listing and for five days prior to the larger survey. During the five-day training, interviewers reviewed the questionnaire item-by-item and engaged in practice and mock interviews. For openended questions, interviewers were trained to probe respondents and record the response verbatim. Toward the end of the training, interviewers practiced the questionnaire on adolescents who were recruited from outside the study area. As many of the topics covered may be considered sensitive, male interviewers interviewed male respondents while females interviewed female respondents. Interviewers paid up to three visits to locate and interview the sampled adolescent.

Informed consent was obtained from all respondents. In addition, informed consent was obtained from the parents or guardians of adolescents when they had resident parents or guardians. Supervisors checked all completed questionnaires for data quality and completeness. Data was entered using Epi-Info and later converted to SPSS 5 for analysis. Direct quotes from open-ended questions were translated and typed into a Word file.

${ }^{4} \mathrm{~A}$ Kish grid is a random number table that can be used as a method for selecting a respondent at random.

${ }^{5}$ Statistical Package for the Social Sciences, Ver. 10.0 


\section{SAmple Characteristics}

A total of 1,865 young people aged 10 to 19 were interviewed, with a response rate of 93 percent. Nearly equal numbers of boys and girls were interviewed. Boys in the sample were more likely to be younger adolescents - aged 10 to 14 - compared to girls. There were no significant differences between boys and girls in terms of school status and educational attainment. ${ }^{6}$ Boys and girls differed significantly in terms of marital status where nearly 30 percent girls had been married compared to only 5 percent of boys. Fully 12 percent of girls are already divorced.

Table 2: Sample characteristics, by sex of respondent

\begin{tabular}{|c|c|c|c|}
\hline Variable & Response category & Boys ( $n=925)$ & Girls $(n=940)$ \\
\hline Age category & $\begin{array}{l}10 \text { to } 14 \\
15 \text { to } 19\end{array}$ & $\begin{array}{l}65.4^{\star *} \\
34.6\end{array}$ & $\begin{array}{l}57.5 \\
42.5\end{array}$ \\
\hline School status & $\begin{array}{l}\text { In school } \\
\text { Out of school }\end{array}$ & $\begin{array}{l}48.7 \\
51.3\end{array}$ & $\begin{array}{l}46.5 \\
53.5\end{array}$ \\
\hline Educational attainment & $\begin{array}{l}\text { No education } \\
1 \text { to } 4 \text { years } \\
5 \text { to } 8 \text { years } \\
9 \text { or more years }\end{array}$ & $\begin{array}{r}45.0 \\
39.7 \\
14.3 \\
1.0\end{array}$ & $\begin{array}{r}49.0 \\
34.9 \\
15.4 \\
0.7\end{array}$ \\
\hline Marital status & $\begin{array}{l}\text { Never married } \\
\text { Currently married } \\
\text { Divorced }\end{array}$ & $\begin{array}{r}94.9 \\
3.6 \\
1.5\end{array}$ & $\begin{array}{l}70.8^{* * *} \\
17.0 \\
12.2\end{array}$ \\
\hline Socio-economic index ${ }^{7}$ & $\begin{array}{l}0 \text { to } 5 \text { household assets } \\
6 \text { to } 15 \text { household assets }\end{array}$ & $\begin{array}{l}58.6 \\
41.4\end{array}$ & $\begin{array}{l}69.3^{* * *} \\
30.7\end{array}$ \\
\hline Area of residence & $\begin{array}{l}\text { Yilimana Densa Woreda } \\
\text { Mecha Woreda }\end{array}$ & $\begin{array}{l}72.4 \\
27.6\end{array}$ & $\begin{array}{l}71.2 \\
28.8\end{array}$ \\
\hline
\end{tabular}

Differences between groups significant at ${ }^{*} p<0.05 ;{ }^{* *} p<0.01 ;{ }^{* * *} p<0.001$

The population of the study areas was quite homogenous in terms of ethnic group and religion. All respondents were from the Amhara ethnic group and all but 10 respondents were Orthodox Christian, with the remainder being Muslim.

\footnotetext{
${ }^{6}$ The fact that boys and girls did not differ in terms of education is contrary to some of the educational statistics for rural Ethiopian adolescents which often reveal significant gender disparities in terms of education. The two study sites were both located near schools, which may have increased young people's access to education, especially girls. In terms of availability of schools, these study sites may not be representative of other rural areas in Ethiopia, where schools are often not located in the immediate vicinity.

${ }^{7}$ In order to measure socio-economic status, respondents were read a list of 15 items or amenities, adapted from the Ethiopia Demographic and Health Survey (2000). Respondents were scored as to the number of items that their household possessed, with possible scores ranging from 0 to 15 .
} 


\section{Parental Survivorshit \& Presence}

Over 30 percent of adolescents have one or both parents dead, and 5 percent were orphans, having lost both parents. Most of the adolescents in the sample had parents who are married to each other, though a significant proportion (12 percent of boys and 17 percent of girls) had parents who are divorced or separated. A considerable proportion of adolescents lived with neither parent, with a significantly greater percentage of girls (31.2 percent) living without parents compared to boys (19.7 percent). The fact that many girls are married partly accounts for the excess of girls not living with parents, with 81 percent of currently married girls not living with parents. At the same time, 15 percent of never married girls are living with no parents. The vast majority of adolescents' parents have never been to school. Ninety-six percent of mothers and 92 percent of fathers have never been to school.

Table 3: Parental survivorship, parental residence, and fostering experiences, by sex

\begin{tabular}{llrc}
\hline Variables & Response categories & Boys $(\mathbf{n}=\mathbf{9 2 5})$ & Girls $(\mathbf{n}=\mathbf{9 4 0})$ \\
\hline Parental Survival & Both parents alive & 69.9 & 67.8 \\
& One parent dead & 25.6 & 26.8 \\
& Both parents dead & 4.5 & 5.4 \\
Marital status of parents & Married & 87.2 & 82.6 \\
& Never married & 0.5 & 0.3 \\
& Divorced/Separated & 12.3 & 17.1 \\
Living Arrangements & Both parents & 57.9 & 49.2 \\
& Mother only & 19.7 & 18.5 \\
& Father only & 2.7 & 1.1 \\
& No parents & 19.7 & $31.2^{* * *}$ \\
Ever Fostered & Yes & 12.9 & 11.6 \\
& No & 87.1 & 88.4 \\
Mother has been to school & Yes & 3.3 & 4.1 \\
& No & 96.7 & 95.9 \\
Father has been to school & Yes & 8.0 & 7.9 \\
& No & 92.0 & 92.1 \\
\hline
\end{tabular}

Differences between groups significant at ${ }^{*} p<0.05 ;{ }^{* *} p<0.01 ;{ }^{* * *} p<0.001$ 


\section{Education \& Livelihoods}

Only about half of the young people in the study areas have been to school. The rates of school attendance in this sample are slightly higher than educational participation rates for rural Amhara generally and the gender disparities in educational participation are not as apparent as they are in other areas. One reason for this could be that, unlike many rural areas in Ethiopia, both of the study areas have schools, giving young people access to education. Among those who had never attended school, the reasons for not attending were significantly different for boys and girls. While a majority of both boys and girls mentioned that their parents could not afford schooling, the second most common reason for girls was marriage (31 percent) and for boys, domestic duties (34 percent).

Because of the work at home, I did not have to time and the chance to go to school. I always look after the cattle and I hate that. (Ambara boy, age 11, not married, never attended school)

Table 4: Education, vocational training and literacy, by sex

\begin{tabular}{lcc}
\hline Variables & Boys ( $\mathbf{n = 9 2 5 )}$ & Girls ( $\mathbf{n = 9 4 0 )}$ \\
\hline Ever attended school & 55.4 & 51.0 \\
Yes & 44.6 & 49.0 \\
No & & \\
Main reason for never attending schoolt & 46.2 & $39.9^{* * *}$ \\
Family could not afford & 33.7 & 14.4 \\
Too many domestic responsibilities & 1.4 & 30.5 \\
Got married & 7.6 & 7.0 \\
Family does not see the benefit & 4.3 & 3.3 \\
School too far, no schools & 6.8 & 4.9 \\
Otherf & & \\
Age of entry into school & 13.2 & $21.2^{* *}$ \\
Before age 8 & 52.9 & 53.3 \\
Age 8 to 10 & 33.9 & 25.5 \\
After age 10 & 3.0 & 2.9 \\
Mean years of education (out of school only) & 0.4 & 0.9 \\
Received vocational training & & \\
Literacy level & & \\
Reads easily & & \\
With difficulty & 27.6 & 25.0 \\
Not at all & 19.9 & 20.2 \\
\hline
\end{tabular}

Differences between groups significant at ${ }^{*} p<0.05$; ${ }^{* *} p<0.01$; ${ }^{* * *} p<0.001$

tAmong those who have never attended school

f"Other" includes death of a family member, no interest, or too young 
The age of entry into school was quite late. Only 13 percent of boys and 21 percent of girls started school before age 8 . Most young people started school between the ages of 8 and 10, but a considerable proportion started after age 10 (34 percent of boys and 26 percent of girls).

While school attendance in the study area was higher compared to other rural areas of Amhara, educational attainment was indeed quite low. Among young people who had attended school, few stayed for long. Among the out-of-school, young people had attained an average of only 3 years of education. As a result, few young people were able to read easily and over half of young people could not read at all. Only 12 respondents had received any vocational training.

I attend school because it is nearby and if I go to school, I can be saved from getting married at an early age. (Amhara girl, age 10, never married, in school, 2 years of education)

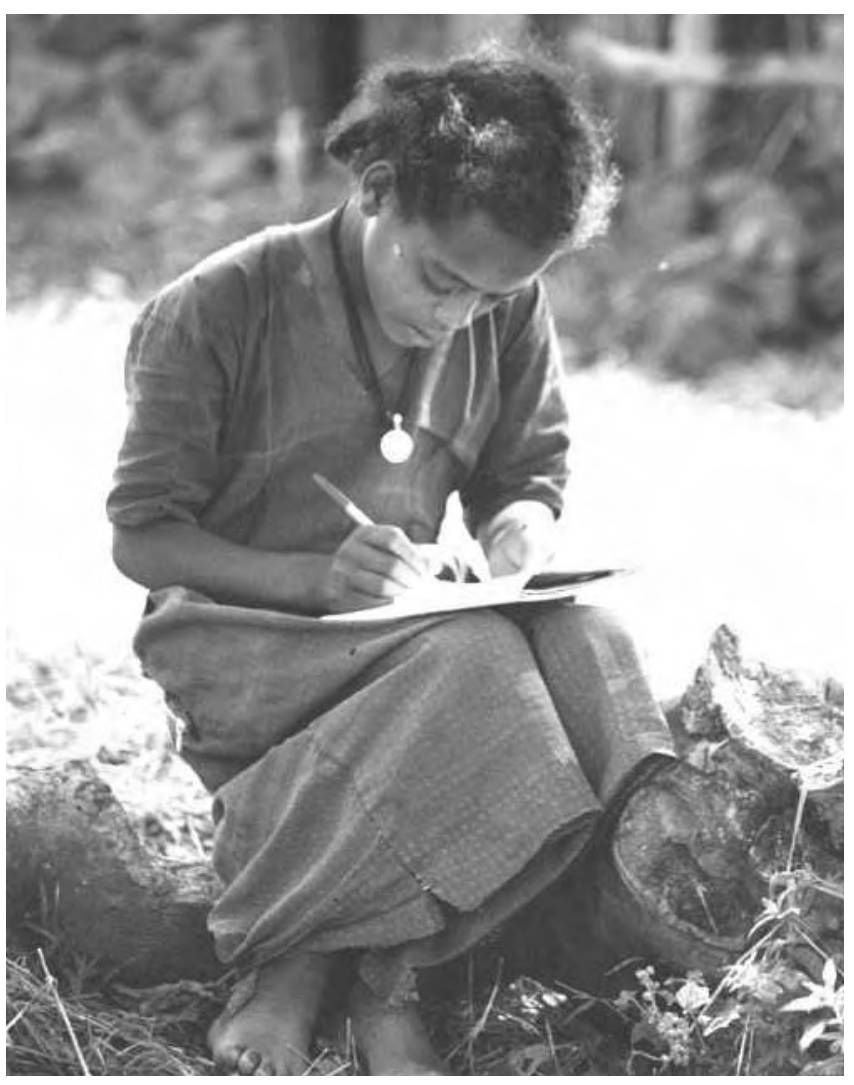




\section{WORK}

\subsection{Paid work}

Few adolescents had ever worked for pay with only 13 percent of boys and 3 percent of girls having worked for pay. Among those who had worked for pay, boys mostly engaged in herding (71 percent) or farming (25 percent), while girls worked as domestic workers (30 percent) or produced the local alcohol, areki (30 percent). Among working adolescents, only a minority kept all their earnings. Fully 14 percent of boys and 23 percent of girls forfeit all their earnings to someone else. Young people's earnings were mainly used for food, clothing or healthcare for the family. A significant proportion said that money was simply given to the families for general support. With few young people earning money and many spending the money that they earned for basic support to families, very few had savings ( 4 percent of boys and 3 percent of girls).

\subsection{Unpaid work}

Almost all adolescents (89 percent of boys and 94 percent of girls) were engaged in unpaid domestic or agricultural work. Boys and girls alike engaged in a considerable amount of unpaid labor (average 30 hours per week for both boys and girls), most of which was devoted to the family farm. Out-of-school youth were working a larger number of hours than their in-school counterparts. Out-of-school boys worked an average of 34.8 hours per week compared to 25.1 for in-school boys; out-of-school girls worked 37.3 hours compared to 23.5 for in-school girls. Most unpaid work was done for adolescents' parents, or, in the case of girls, for their spouses.

\subsection{Time use}

Figure 1 shows the time use of rural adolescents by sex and school status. Even when in school, rural adolescents spend a significant amount of time working, especially unpaid work. Once out of school, the time that adolescents spend on work increases dramatically, with out-of-school adolescents spending more than 70 percent of their waking hours working.

Figure 1. Time Used of adolescents, by sex and school status Mean percent of hours spent in activities

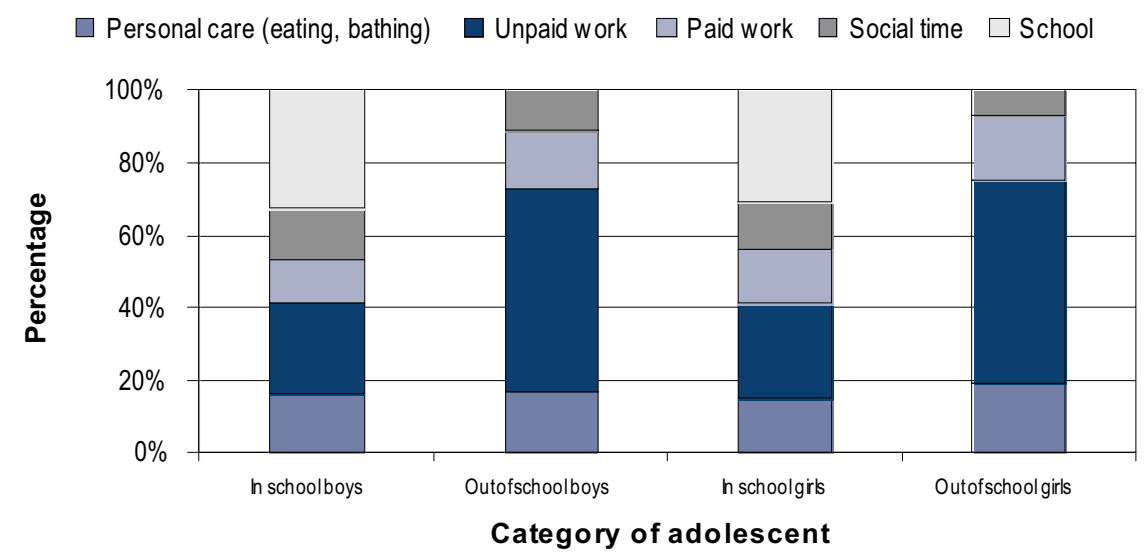


The place where we fetch water is far away and the boys hassle us on the way. Especially if there are no older people with us, they would chase us and break our pots. (Girls age 12, never married, in school, 4 years education)

\section{Social Networks, Support, \& Mobility}

Boys appear to have more friends than girls, with boys reporting a mean number of 2.2 friends compared to girls' 1.9. Further, married and divorced girls had far fewer friends than their unmarried counterparts (mean 2 friends for unmarried girls and 1.6 friends for ever married girls). Most of young people's closest friends were, in fact, family members ( 58 percent of boys and 61 percent of girls) with many adolescents naming aunts and uncles or other relatives as their closest friend.

Indeed, boys seem to have larger social networks and support within their communities. Significantly more boys reported having many friends, having people who could offer shelter or a loan if they were in need, and having a place in the area where they meet their friends (Table 5). A considerable number of young people were scared of being beaten by someone in their neighborhood and a significant number of young people, especially girls, were afraid of being raped. A number of young people reported that they have been molested and teased in their neighborhood:

The place where we fetch water is far away and the boys hassle us on the way. Especially if there are no older people with us, they would chase us and break our pots. (Girls age 12, never married, in school, 4 years education)

Table 5: Community support, perceptions of safety and experience of crime, by sex (Percentage agreeing with the statement)

\section{Experience of social support in the neighborhood}

You have many friends in the neighborhood

If you didn't have a place to sleep, there is someone in your neighborhood who would take you in

If you needed money urgently, there is someone in your neighborhood who you could borrow from

You have a place in the neighborhood (other than home or school) to meet your same sex friends

\section{Feelings of well-being and comfort in the neighborhood}

You know of girls in your neighborhood who have been raped

You are scared of being beaten by someone in your neighborhood

At times you are scared that you will be raped in your neighborhood

\section{Experience of harassment and crime}

You have been groped by someone of the opposite sex in your neighborhood 
It is perhaps because of boys' larger social and support networks, that they are also more engaged in civic life in their area (Table 6). When asked if they had participated in social events in the last week, except for attending Church, boys were significantly more likely to have been engaged. Likewise, boys were more likely to have had media exposure through the radio compared to girls. Girls were further analyzed to examine whether married girls had differential participation compared to unmarried girls. ${ }^{8}$ Married girls were more likely to attend Church and participate in coffee ceremonies while unmarried girls were more likely to have socialized with their same sex friends. Married girls are significantly less likely to have been exposed to radio or television compared to their unmarried counterparts, reflecting their isolation compared to their unmarried counterparts and to boys.

Table 6: Participation in social events and media exposure, by sex and marital status

\begin{tabular}{|c|c|c|c|c|}
\hline & $\begin{array}{l}\text { All boys } \\
(n=925)\end{array}$ & $\begin{array}{l}\text { All girls } \\
(n=937)\end{array}$ & $\begin{array}{c}\text { Never married girls } \\
(\mathrm{n}=663)\end{array}$ & $\begin{array}{l}\text { Ever married girls } \\
\qquad(n=274)\end{array}$ \\
\hline \multicolumn{5}{|l|}{ Social participation in the last week } \\
\hline Socialized with friends & $80.1^{1 * *}$ & 70.3 & $71.9 \sim$ & 66.4 \\
\hline Gone outside your home to meet same sex friends & $36.1^{* * *}$ & 21.2 & $24.0^{* *}$ & 14.6 \\
\hline Gone to a church or mosque & 17.2 & $25.0^{* * *}$ & 21.9 & $32.8^{* *}$ \\
\hline Participated in a coffee ceremony & $81.6^{\star \star \star}$ & 76.7 & 75.0 & $80.7 \sim$ \\
\hline \multicolumn{5}{|l|}{ Media exposure in the last week } \\
\hline Listened to the radio & $37.2^{\star \star \star}$ & 24.4 & $27.0^{* *}$ & 17.9 \\
\hline Watched TV & 9.1 & 7.8 & $9.5^{\star *}$ & 3.6 \\
\hline
\end{tabular}

Differences between groups significant at $\sim p<0.10{ }^{*} p<0.05 ;{ }^{* *} p<0.01 ;{ }^{* * *} p<0.001$

${ }^{8}$ Similar analysis was not conducted for boys as there were too few married boys in the sample. 


\section{Reproductive Health \& Experience WITH HIV/AIDS}

The reproductive health knowledge of adolescents in rural Amhara was relatively low compared to adolescents in Addis Ababa, as well as those in other areas. ${ }^{9}$ Very few adolescents could correctly name the fertile period during a woman's cycle, with married adolescents having no better knowledge than the unmarried. A majority of adolescents had heard about contraceptive pills and injectables. Surprisingly, only 35 percent of young people had heard about condoms ( 44 percent of boys and 27 percent of girls). Roughly one out of ten young people were not aware of any method (Table 7).

Table 7: Reproductive health knowledge, by sex

Boys
$(n=914)$$\quad \begin{gathered}\text { Girls } \\ (n=938)\end{gathered}$

Fertility and family planning

Know the fertile period

$5.7 \quad 14.5^{\star * *}$

Know about contraceptive pills

$88.2^{*} \quad 84.1$

Know about injectables

$87.4 \quad 85.1$

Know about condoms

$43.5^{\star * *} \quad 26.9$

Do not know about any FP method

$9.4 \quad 12.5^{*}$

Sexually transmitted diseases and HIVIAIDS

Know that a woman cannot always tell if she has an STI

$31.239 .5^{*}$

Know that HIV is not just transmitted in towns

$28.137 .6^{* \star *}$

Know that most people do not get HIV from accidents with sharp objects

$21.6^{*} \quad 18.6$

Know that one cannot get HIV from eating utensils

$27.1 \quad 25.6$

Know withdrawal does not protect against HIV

$34.0 \quad 34.5$

Know that a woman cannot always tell if a man has an STI

$45.7 \quad 42.6$

Know that there is no cure for AIDS

$79.5^{* * *} \quad 61.1$

Know that a healthy looking person can have HIV

74.0

74.1

Mentioned sexual intercourse as a mode of HIV transmission

81.8

85.1

Differences between groups significant at $\sim p<0.10{ }^{*} p<0.05 ;{ }^{* *} p<0.01$; ${ }^{* * *} p<0.001$

'See for example, Erulkar, Mekbib, Simie and Gulema, (2004), and Govindasamy, Kidanu, and Bantayerga (2002) 
Adolescents were fairly knowledgeable about basic information on HIV such as that sexual intercourse is a mode of HIV transmission (84 percent), that a healthy looking person can be infected with HIV ( 74 percent), and that there is no cure for AIDS (70 percent). A considerable number of young people had misconceptions about HIV or were not sure of information. Only 33 percent knew that HIV is not just a disease transmitted in towns and only 20 percent knew that accidents with sharp objects are not the main mode of HIV transmission.

Sixteen percent of young people know someone who has HIV or who has died of AIDS. Most of the people they know are neighbors or acquaintances, but 5 percent report that they have lost a family member to AIDS. Nine percent of all adolescents and 12 percent of sexually active adolescents worry that they, themselves might be HIV positive. Twentyone percent report that they know where to get tested for HIV and 15 percent say that they would like such a test. Only 7 adolescents reported that they had been tested for HIV. 


\section{Exposure to HIV/AIDS Messages}

Young people were asked a series of questions on exposure to HIV/ AIDS messages in the last year including lectures at school, lectures outside school, dramas, and radio messages. Overall, 42 percent of young people have received information about HIV in the past year, with boys significantly more likely to have heard information compared to girls (Table 8). Further, boys were significantly more likely to have heard HIV messages in school lectures, through dramas and through the radio, which reflects their greater exposure to these mediums. Considering never married versus ever-married young women, married adolescents were disadvantaged compared to their unmarried counterparts. Only 30 percent of married adolescents had heard an HIV message in the last year compared to 46 percent of their unmarried counterparts, a difference that was statistically significant. Likewise, unmarried girls were significantly more likely to have gotten HIV information through lectures, dramas and radio.

While ever-married girls are the least likely to have received information, they are perhaps at highest risk of infection. Never married girls in the study area are highly unlikely to have had sex and therefore have limited exposure to HIV risk (see Sexual Activity \& Marriage). There is emerging evidence that married adolescents are at extremely high risk of HIV infection, which is attributed to frequent unprotected sex and the fact that their partners are much older and more likely to be infected (Glynn et al 2002, Clark 2004). The fact that the most at-risk married adolescent girls are the least likely to receive HIV information highlights the need to target this high risk and neglected group of young people.

Table 8: Exposure to HIV/AIDS information in the last year, by sex and marital status

\begin{tabular}{|c|c|c|c|c|}
\hline & $\begin{array}{l}\text { Boys } \\
(n=925)\end{array}$ & $\begin{array}{c}\text { Girls } \\
(n=936)\end{array}$ & $\begin{array}{c}\text { Never married girls } \\
(\mathrm{n}=662)\end{array}$ & $\begin{array}{l}\text { Ever married girls } \\
\qquad(n=274)\end{array}$ \\
\hline Heard any HIVIAIDS message in the last year & $53.2^{\star \star \star}$ & 41.6 & $46.3^{\star \star \star}$ & 30.1 \\
\hline Attended HIVIAIDS lecture in school & $37.8^{\star \star \star}$ & 23.3 & $25.7^{\star \star \star}$ & 9.9 \\
\hline Attended HIVIAIDS lecture outside school & 23.6 & 21.0 & $29.3^{\star \star \star}$ & 9.1 \\
\hline Attended a drama on HIV/AIDS & $20.2^{\star *}$ & 14.9 & $17.3^{\star * *}$ & 9.1 \\
\hline Heard a radio spot about HIVIAIDS & $29.1^{* *}$ & 23.7 & $27.5^{\star \star \star}$ & 14.3 \\
\hline Received HIVIAIDS information from a healthcare provider & 13.8 & 16.7 & 16.1 & 18.2 \\
\hline
\end{tabular}

Differences between groups significant at $\sim p<0.10{ }^{*} p<0.05 ;{ }^{* *} p<0.01$; ${ }^{* *} p<0.001$ 


\section{Sexual Activity \& Marriage ${ }^{10}$}

Adolescent sexual activity occurred within the context of marriage, a finding consistent with other studies of Ethiopian youth. ${ }^{11}$ Ninety-nine percent of sexually active adolescent girls were married and all but two had first sex with their husband or fiancée. Among boys, only 22 were sexually experienced and 86 percent of these boys had first sex within marriage. Put another way, a greater proportion of girls (23 percent) were sexually experienced than boys ( 2 percent) simply because girls were more likely to be married. Therefore, within this rural population, marriage largely drove the timing of first sex.

Marriage is notoriously hard to measure since it is often a process that takes place over time rather than a single event, a pattern especially true in sub-Saharan Africa (Meekers 1992). The question of whether girls who are married early in Amhara are actually married or betrothed has undergone considerable discussion. Though girls marry at very young ages, they may not have intercourse until years later, causing some to argue that they are not married, but betrothed. On the other hand, girls' moving residence at the point of marriage suggests that the shift in her status is greater than the word "betrothed" implies. In in-depth interviews that comprised the formative research for this survey, girls described themselves as "married," and not "engaged" or "promised." In the context of this survey, we considered an adolescent to be married if they defined themselves as married. Indeed, the majority of girls left their own residence at the point of marriage, suggesting a major shift in status following the event.

Marriage for girls occurred at an earlier age than for boys (Figure 2). Girls' marriages occurred at extremely early ages, with 14 percent of girls married by age 10,39 percent of girls married by age 15 and 56 percent married by age 18 . The rate of early marriage in the study area is slightly lower than the same estimates from the DHS for Amhara region as a whole (42 percent married by age 15; 80 percent married by age 18). Differences could be due the proximity of these rural areas to the regional capital Bahir Dar and to the observed rates of school attendance among girls in these areas:

I attend school because it is nearby and if I go to school, I can be saved from getting married at an early age. (Amhara girl, age 10, never married, in school, 2 years of education)

\footnotetext{
${ }^{10}$ This section includes information on girls' marriages only as boys' marriage occurs much later Only 35 boys in the sample were married.

${ }^{11}$ See Govindasamy, Kidanu, and Bantayerga (2002)
} 
Figure 2. Cumulative proportion of boys and girls who are married, by age

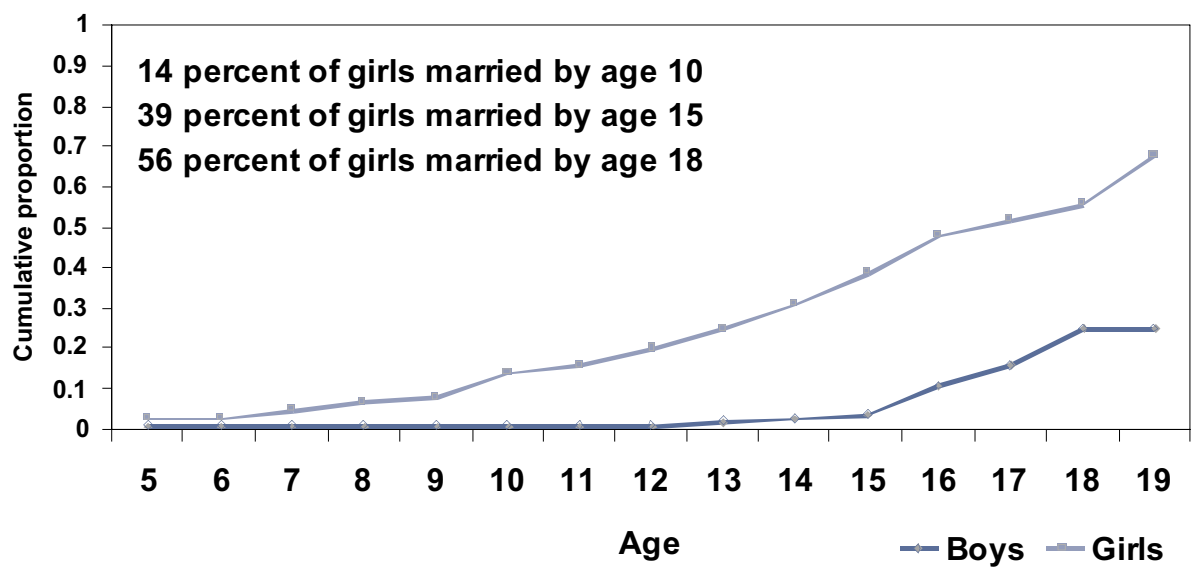

\subsection{Marriage and education}

Most married girls never had the chance to go to school. Eighty-three percent of ever-married girls had never been to school compared to 35 percent of never-married girls, a difference that was statistically significant. Among married girls, only 12 reported leaving school because of the marriage, largely because the vast majority of married girls had never been to school in the first place. Among married girls who had never been to school, 59 percent gave marriage as the reason why they did not attend and 25 percent said that their parents could not afford to send them. Among never-married girls who had never attended school, the main reason for non-attendance was that the family could not afford school ( 54 percent) followed by too many domestic responsibilities (20 percent). Indeed, the married girls often regretted not being able to get an education:

We work day in and day out. I haven't seen the use of my marriage yet. I would have liked an education but I was not able to. Education is useful. First, you can earn money without being exhausted. And second, the child can grow eating whatever he likes and dressing however he likes. But here, a child grows up with one dress. (Ambara girl, age 16, married at age 6)

At the same time, married girls in the sample do not appear to come from poorer households compared to never married girls. This is likely because households in the sample had very similar levels of poverty, with negligible differences between households in terms of assets. ${ }^{12}$ Similarly, there were no significant differences in parental education between girls who were married early versus those who were not. The vast majority of married adolescents' parents had no education at all ( 94 percent of fathers and 98 percent of mothers).

${ }^{12}$ The survey asked respondents about personal assets, assets of parents, and assets of the household in which they were currently living (most often their in-laws or husbands). This allowed socioeconomic status measurement of the respondents' natal household and not just their current household, as is most common in surveys. 


\subsection{Decision-making and consent to marry}

In Amhara Region, the most extreme forms of child marriage are practiced. In some cases children are married very young and tradition mandates that a girl gets married before first menstruation. Among ever married girls $^{13}$ in the sample, 28 percent had married before age 10, 33 percent had married between the ages of 10 to 12, 27 percent had married between the aged 13 to 15 , and 12 percent married after age 15 . With 51 percent of married adolescents married before age 13, it does suggest that many parents felt pressured to marry girls off before first menses. Fully 87 percent of married girls in the sample got married before their first menses (71 percent) or the same year that they started menstruating (16 percent).

The vast majority of girls did not know their husband beforehand, did not know they were about to be married, and did not want to be married. Lack of knowledge and consent to marriage is most pronounced among girls married at the earliest ages. Even among those married after the age of 15 , the majority did not know about the impending marriage and less than half wanted to marry or consented to it.

Table 9: Girls' knowledge and consent to marriage, by age at marriage

\begin{tabular}{lccccc}
\hline & $\begin{array}{c}\text { All married } \\
\text { girls }(\mathrm{n}=\mathbf{2 7 5})\end{array}$ & $\begin{array}{c}\text { Married below } \\
\text { age } \mathbf{1 0}(\mathrm{n}=\mathbf{7 2})\end{array}$ & $\begin{array}{c}\text { Married age } \\
\text { 10 to 12 }(\mathrm{n}=\mathbf{8 7})\end{array}$ & $\begin{array}{c}\text { Married age } \\
\mathbf{1 3} \text { to } 15(\mathrm{n}=69)\end{array}$ & $\begin{array}{c}\text { Married age } \\
\mathbf{1 6 +}(\mathrm{n}=\mathbf{3 1})\end{array}$ \\
\hline Knew spouse beforehand & 5.5 & 2.8 & 2.3 & 7.2 & 12.9 \\
Knew about marriage beforehand & 15.3 & 5.6 & 12.6 & 23.2 & 25.8 \\
Wanted to get married at the time & 14.9 & 2.8 & 9.2 & 24.6 & 41.9 \\
Consented to the marriage & 19.6 & 6.9 & 13.8 & 29.0 & 48.4 \\
\hline
\end{tabular}

Many young women expressed helplessness in the decision to marry:

That is the way it is in the countryside. They [adults] do it for their own benefit. We were children and we didn't know what they were doing to us... Even in this time of Christianity, things are getting worse. Parents are fighting over each other's children. Like I was telling you, I didn't understand what they were doing to me. (Ambara girl, age 19, married at age 3)

\footnotetext{
${ }^{13}$ The figures cited for age at marriage differ from those cited earlier as earlier figures are based on a life table of all girls, whether married or unmarried, and these figures are based on ever married girls only.
} 


\subsection{Post marital living arrangements}

Once a girl is married, her living arrangements may or may not change immediately. Traditionally, a girl who is married very young may either remain with her parents, or may move to her in-law's or husband's house. Frequently, she shuttles between the two households, providing labor in each of those households. The post-marital arrangement tends to differ depending on the girl's age at marriage, though marriage does mark a change in living arrangements for most girls. Among those married below age 10, 58 percent remained with their parents; 15 percent went to live with their husbands or in-laws, and 26 percent alternated between their natal home and their marital home. Among girls married on or after the age of 10, they are far more likely to relocate to the marital home. Among girls married at age 10 to 12,49 percent relocated to the marital home and only 29 percent remained with their parents.

\subsection{Spouses and partnerships}

All but three girls were younger than their spouses, with girls being an average of 6.2 years younger. Sixteen percent of married girls were 10 or more years younger than their spouse. There were not wide educational differences between partners as both partners tended to be unschooled. Nine percent of married girls were in polygamous unions.

Table 10: Girls' living arrangements following marriage, by age at marriage

\begin{tabular}{|c|c|c|c|c|c|}
\hline & $\begin{array}{l}\text { All married girls } \\
\quad(n=275)\end{array}$ & $\begin{array}{l}\text { Married below } \\
\text { age } 10(n=72)\end{array}$ & $\begin{array}{c}\text { Married age } \\
10 \text { to } 12(n=87)\end{array}$ & $\begin{array}{c}\text { Married age } \\
13 \text { to } 15(n=69)\end{array}$ & $\begin{array}{c}\text { Married age } \\
16+(n=31)\end{array}$ \\
\hline Lived with spouse permanently & 28.4 & 5.6 & 33.3 & 37.7 & 51.6 \\
\hline Lived with in-laws & 17.1 & 9.7 & 16.1 & 27.5 & 19.4 \\
\hline Lived with own parents & 30.5 & 58.3 & 28.7 & 10.1 & 16.1 \\
\hline Back and forth between in-laws and parents & 24.0 & 26.4 & 21.8 & 24.6 & 12.9 \\
\hline
\end{tabular}




\subsection{Sexual initiation}

For 99 percent of girls in rural Amhara, sexual initiation occurred within marriage. Only two sexually experienced girls had sex pre-maritally. While many girls marry and move to their in-laws' or husbands' home, the marriage may not be consummated immediately. Fourteen percent of currently married girls have not had sex, with most of these being the youngest married girls. At the same time, sexual initiation among married girls is very early. Eight percent of married girls have had sex by age 10, 26 percent had sex by age 12 , and 70 percent had sex by age $15 .{ }^{14}$ The majority of girls (69 percent) had not started menstruating when they had sex for the first time.

It was mainly girls' spouses and in-laws who decided when the marriage would be consummated. Only 2 percent of married girls participated in the decision to have sex for the first time, while 72 percent of girls' husbands made the decision or were involved, and 29 percent of in-laws were involved in the decision.

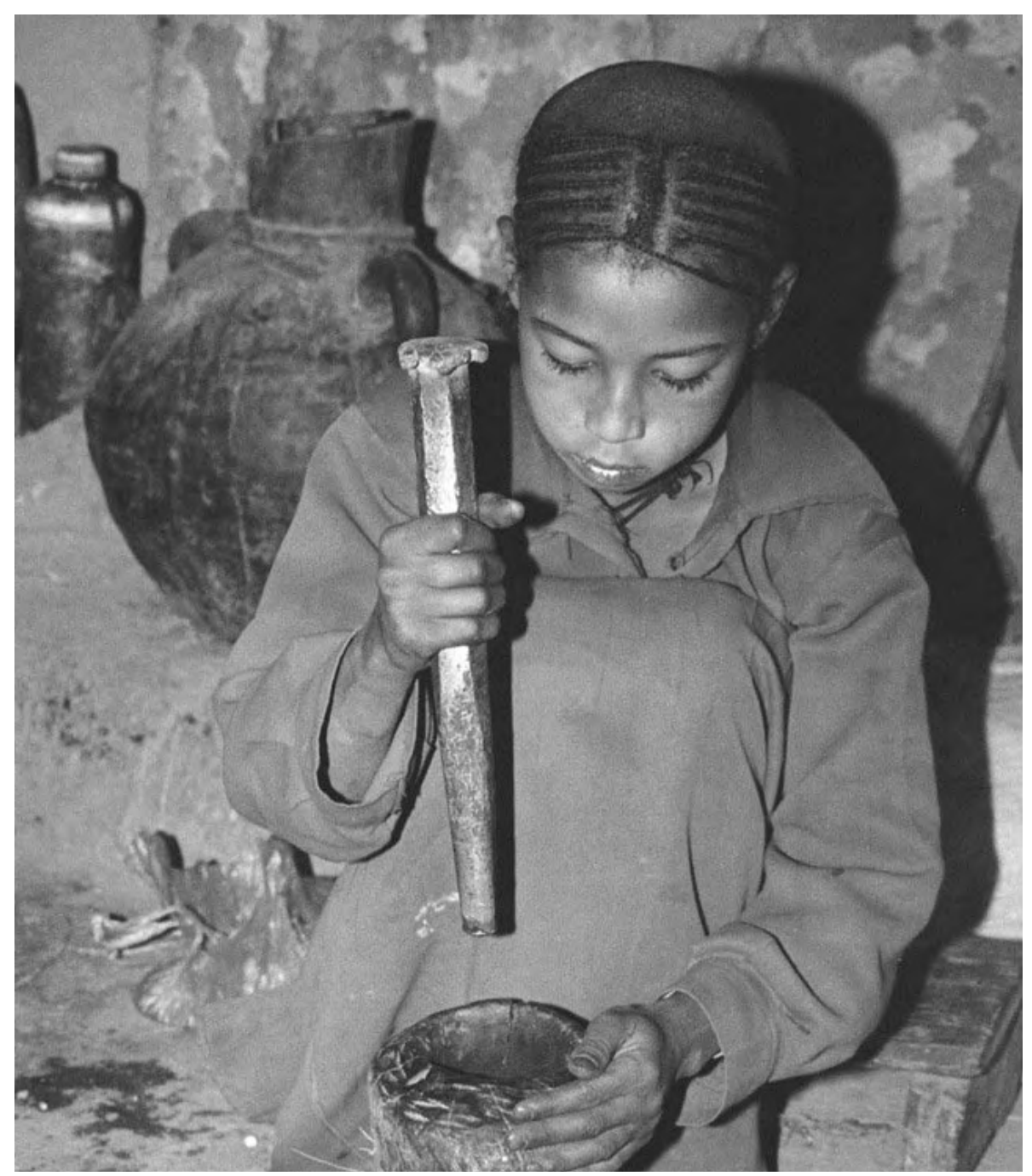

I hate early marriage. I was married at an early age and my inlaws forced me to sleep with my husband and he made me suffer all night. After that, whenever day becomes night, I get worried thinking that it will be like that. This is what I hate most. (Amhara girl, age 11 , married at age 5)

${ }^{14}$ Calculation based on survival analysis of all married girls 
Table 11: Context of sexual initiation, by age at marriage

\begin{tabular}{lcccccc}
\hline & $\begin{array}{c}\text { All married girls } \\
(\mathrm{n}=275)\end{array}$ & $\begin{array}{c}\text { Married below } \\
\text { age } 10(\mathrm{n}=72)\end{array}$ & $\begin{array}{c}\text { Married age } \\
\text { 10 to 12 }(\mathrm{n}=87)\end{array}$ & $\begin{array}{c}\text { Married age } \\
\text { 13 to 15 }(\mathrm{n}=69)\end{array}$ & $\begin{array}{c}\text { Married age } \\
16+(\mathrm{n}=31)\end{array}$ \\
\hline Did not want to have sex when they did & 82.0 & 92.3 & 86.7 & 78.7 & 66.7 \\
Were forced to have sex against their will & 81.4 & 89.7 & 88.4 & 78.7 & 60.0 \\
\hline
\end{tabular}

Eighty-two percent of married girls would have preferred not to have sex when they did and 81 percent were forced to have sex against their will. Most girls did not consent to their marriage, did not want to marry at that time, and were forced to have sex against their will. Sexual initiation for these girls is effectively rape, even though occurring within marriage. The younger the girl when she is married, the more likely that she was forced to have sex (Table 11).

When girls described their sexual initiation, it was indeed traumatic:

I hate early marriage. I was married at an early age and my in-laws forced me to sleep with my husband and he made me suffer all night. After that, whenever day becomes night, I get worried thinking that it will be like that. This is what I hate most. (Ambara girl, age 11, married at age 5)

A girl came to our area after she got married to her husband. When she refused to have sex with him, he beat her up. Then my parents and some other people intervened. After that, she ran away in the middle of the night to herparents and said to them that she wants to go to school. But, since they refused to send her to school, they married her again. Then she hanged herself... She didn't want that [marriage], but we don't have a choice, that's why. (Ambara girl, age 15, married at age 4)

R: I had a brother. He was older than me. He was married to a girl much smaller than me. She resisted him and he raped her. She was just a child - she was 11 years old then. She was not happy at all. She used to be afraid of him.

I: What did you do for her?

R: Nothing. We don't stick our noses in their business. They are husband and wife. (Ambara girl, age 19, married at age 3)

Within the relationship, most girls (85 percent) report that they are not able to refuse their husbands sex. At the same time, when asked whether their spouse has always been faithful, 41 percent of girls said 'no' or they do not know, and 11 percent of girls say they are scared that their husband will give them HIV/AIDS. 


\subsection{Divorce}

With high rates of early marriage, 12 percent of all adolescent girls in the sample were already divorced. While girls were not involved in the decision to marry, they mainly made the decision to divorce, and 82 percent of girls said that they were happy they got divorced. For many girls, the divorce allowed them to enter or resume schooling and a number of girls cited divorce because of physical abuse in the marriage:

I am able to get an education now. But if I had lived with him, I don't think he would have allowed me to attend school. The fact that I divorced him has enabled me to go to school. (Amhara girl, age 15, married at age 5, later divorced, in school, 4 years of education)

I am now free from the physical abuse and I live with my parents with dignity. (Ambara girl, age 15, married at age 11 to an 18 year old man, divorced at age 14, never been to school)

\section{Pregnancy \& Births}

For girls in rural Amhara, just as sexual activity is almost universally confined to marriage, so is childbirth. Only one girl in the sample had given birth out of wedlock. Over one third (37 percent) of the married girls had given birth, with some girls having as many as three children before their twentieth birthday. With early marriage comes early childbirth. Twelve percent of ever-married girls have given birth by age 15 and 31 percent give birth by age 17. And just as girls felt their marriages were mistimed, so did they feel their pregnancies were too early. Sixty-one percent of girls did not want the pregnancy at the time they did. Fortyfive percent said they were made pregnant because they were forced to have sex against their will. Seventeen percent of ever-pregnant girls said that they considered ending the pregnancy and 14 girls in the sample admitted that they had ended a pregnancy.

I remember one girl in the countryside, she was under age and she had a sex and she had a severe womb problem and finally she died....She was sixteen. I only know that she was not able to undergo labor and she died. I was afraid Ithat I would get pregnant] after I got married. (Amhara Ethiopia girl age 17, never been to school, married at 8, escaped marriage and came to Addis Ababa at age 12)

\subsection{Prenatal care and childbirth}

The vast majority of girls did not have prenatal care during their first pregnancy (81 percent). Ninety-five percent of girls gave birth at home, mostly at their mothers' house (64 percent), but also with their motherin-law (31 percent). For nearly half of the girls, the birth was assisted by a traditional birth attendant ( 48 percent), or a mother or other relative (38 percent)
I am able to get an education now. But if I had lived with him, I don't think he would have allowed me to attend school. The fact that I divorced him has enabled me to go to school. (Amhara girl, age 15 , married at age 5 , later divorced, in school, 4 years of education) 


\section{Implications for Programs}

\subsection{Recognize the diversity of young people through age and gender specific programming}

Research and programs for young people tend to homogenize the adolescent population into one genderless mass, with little regard to age or social context. Adolescent boys and girls experience rapid, intense, and gendered biological and social changes between the ages of 10 to 19. The changes and needs experienced by a 12-year-old girl are considerably different from an 18 -year-old boy, not to mention the differing nature of their relationships with family, culture and society. Yet, few programs acknowledge those differences. Instead, most programs implicitly assume that young people exist in a vacuum - that they have complete autonomy and control over what happens to them and that socio-cultural realities do not factor in. Greater segmentation of the adolescent population is needed in the design and content of programs. This includes attention to the specific circumstances of young people in rural settings, to the needs of young people in different age groups and to the distinct needs of boys and girls in different circumstances, including marriage.

\subsection{Design programs that are appropriate to the context, including expanding education in rural setting}

Programming for adolescents has centered on a small set of intervention models including youth centers, peer education, and youth friendly services. However, little attention has been paid to the in-built assumptions surrounding these models. For example, while peer education is a very popular program model, it assumes that young people have peers in the first place. Many of the young people, especially girls, reported that they have no friends. Youth centers are probably not appropriate for rural environments given that the rural population is disbursed and many young people are engaged in agricultural responsibilities and have no time to visit a center.

In fact, what young people in this study seemed to value the most was education. Many rural young people missed the opportunity to go to school and regretted not having that chance. Poverty, the pressure of agricultural work, and early marriage were cited as reasons for not going to school. Eighty-five percent of married girls had never been to school and many girls in school feared that their parents would take them out of school and marry them off. Educational opportunities for young people should be expanded, including non-formal education and innovative ways to reach youth with considerable domestic duties and girls who are married.

\subsection{Programs to reduce social isolation}

Many rural young people are isolated. A large proportion never benefit from the experience of schooling and spend a considerable amount of time doing work for the family, especially on the family farm. Young people who are isolated, have few friends, and have limited support networks are likely to be vulnerable and not likely to be reached by existing programs. Mechanisms to build social support networks are 
needed, especially for the most isolated, out-of-school adolescents, including married adolescent girls.

\subsection{Programs to delay marriage and support married adolescent girls}

About one third of the adolescent girls interviewed in this study were married during childhood or adolescence. Their experience of marriage was often traumatic, with their not knowing what was happening to them and not giving their consent to marriage. The majority of girls were forced to leave their parents or were expected to spend time in both their husbands' homes and their natal homes. For the vast majority of girls, sexual initiation was early, unwanted, and traumatic, and pregnancy was most often unwanted and considered too early. Eighty-five percent of victims of early marriage had never been to school and they were less likely to have friends, social support, or to be engaged in civic life. With emerging evidence that early marriage is a risk for HIV infection, these most vulnerable girls are largely invisible, untouched by policy and programs.

Programs to delay girls' marriages and to support girls within marriage are critical. Adolescent sexual activity occurred within the context of marriage, with 99 percent of sexually active adolescent girls married and all but two having had first sex with their husband or fiancée. Delaying girls' marriages will, in effect, delay sexual initiation, childbirth, and the beginning of reproductive risk. Expanding educational opportunities may assist delaying girls' marriages. In addition, parents' awareness that early marriage is not protective of girls but is a risk, is critical. In addition, mechanisms such as livelihoods activities for girls will change the value of girls in their families' eyes, making them more likely not to marry them off. Equally, married girls need supportive programs. Programs to combat married girls' social isolation and provide them with mentoring opportunities are critical. As married girls are at the beginning of their sexual and reproductive lives, they need linkage to reproductive health resources, information and support.

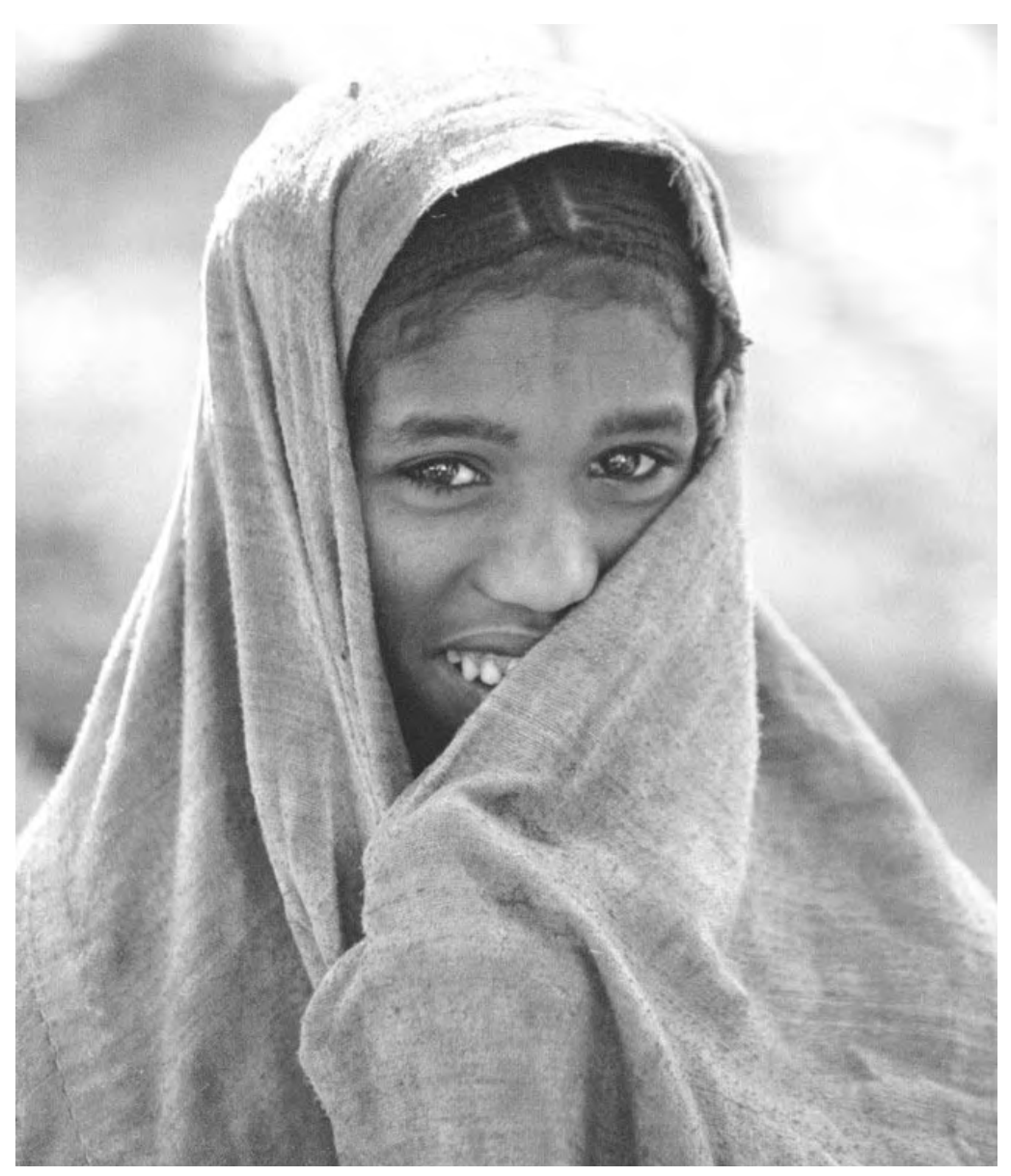




\section{REFERENCES}

Adamu R, Mulatu MS, Haile SI "Patterns and correlates of sexual initiation, sexual risk behaviours, and condom use among secondary school students in Ethiopia" Ethiopian Medical Journal, 2003: 41:163-177.

"AIDS in Ethiopia" Ministry of Health Disease Prevention and Control Dept., 4th ed., Oct, 2002.

Clark S, "Early marriage and HIV risks in sub-Saharan Africa" Studies in Family Planning, 2004: 35(3) 149-160.

Erulkar A, Mekbib T, Simie N, Gulema T "Adolescent life in low income and slum areas of Addis Ababa Ethiopia" Addis Ababa: Population Council and Ministry of Youth Sports and Culture, December 2004.

"Facts about adolescent from the Demographic and Health Survey: Statistical tables for program planning: Ethiopia 2000" New York: Population Council, 2002.

Fekadu Z "Casual sex debuts among female adolescents in Addis Ababa, Ethiopia" Ethiopian Journal of Health and Development, 2001:15(2):109-116.

Glynn, JR, et al. 2001. "Why do Young Women have a much Higher Prevalence of HIV than Young Men? A Study in Kisumu, Kenya and Ndola, Zambia," AIDS, 2001; 15 (suppl 4): S51-S60.

Govindasamy P, Kidanu A, Bantayerga H, Youth Reproductive Health in Ethiopia, Calverton MD: ORC Macro, November 2002.

Helitzer-Allen D, Makhambera M., Wangel AM "Obtaining sensitive information: The need for more than focus groups" Reproductive Health Matters, 1994: 3: 7582.

Kish L, Survey Sampling, New York: Wiley, 1965.

Meekers D, "The process of marriage in African societies: A multiple indicator approach," Population and Development Review,18, no. 1:61-78.

Mensch B, Hewett P, Erulkar AS. "The Reporting of Sensitive Behavior among Adolescents: A Methodological Experiment in Kenya," Demography, 2003:40(2), May.

Mensch B, Bruce J., Greene M, The uncharted passage: Girls' adolescence in the developing world. New York: Population Council, 1998.

Ministry of Health (MOH) Disease Prevention and Control Department, AIDS in Ethiopia, 4th Edition, October, 2002.

UNAIDS, "Number of women living with HIV increases in each region of the world" www.unaids.org (accessed November, 2004).

"UNAIDS/WHO epidemiological fact sheets on HIV/AIDS and Sexually Transmitted Infections, 2004 Update," www.unaids.org (accessed November, 2004).

Versnel M, Berhane Y, Wendte J, "Sexuality and contraception among never married high school students in Butajira, Ethiopia" Ethiopian Medical Journal, 2002: 40: 41-51. 


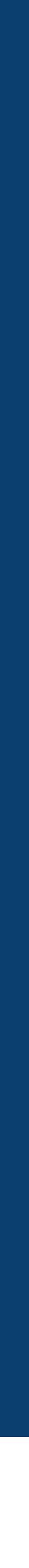

